\title{
Randomized phase 3 open label study of quality of life of patients on Pemetrexed versus Erlotinib as maintenance therapy for advanced non squamous non EGFR mutated non small cell lung cancer
}

\author{
Vijay Patil ${ }^{1,7, *}$, Amit Joshi ${ }^{1,7, *}$, Vanita Noronha ${ }^{1,7}$, Vivek Agarwala ${ }^{1,7}$, Anuradha \\ Chougule $^{1,7}$, Sadhana Kanan ${ }^{2,7}$, Atanu Bhattacharjee ${ }^{3,7}$, Arun Chandrasekharan ${ }^{1,7}$, \\ Nikhil Pande ${ }^{1,7}$, Vijai Simha ${ }^{1,7}$, Supriya Goud ${ }^{1,7}$, Sucheta More ${ }^{1,7}$, Rajiv Kumar ${ }^{4,7}$, \\ Abhishek Mahajan ${ }^{5,7}$, Amit Janu ${ }^{5,7}$, Nilendu Purandare ${ }^{6,7}$ and Kumar Prabhash ${ }^{1,7}$ \\ ${ }^{1}$ Department of Medical Oncology, Tata Memorial Hospital, Mumbai, India \\ ${ }^{2}$ Department of Biostatistics, Advanced Center for Treatment, Research, and Education in Cancer, Mumbai, India \\ ${ }^{3}$ Section of Biostatistics, Centre for Cancer Epidemiology, Tata Memorial Hospital, Mumbai, India \\ ${ }^{4}$ Department of Pathology, Tata Memorial Hospital, Mumbai, India \\ ${ }^{5}$ Department of Radiology, Tata Memorial Hospital, Mumbai, India \\ ${ }^{6}$ Department of Nuclear Medicine, Tata Memorial Hospital, Mumbai, India \\ ${ }^{7}$ Homi Bhabha National Institute, Mumbai, India \\ "These authors contributed equally to this work \\ Correspondence to: Kumar Prabhash, email: kumarprabhashtmh@gmail.com \\ Keywords: maintenance; pemetrexed; erlotinib; NSCLC \\ Received: February 04, $2019 \quad$ Accepted: August 29, $2019 \quad$ Published: October 29, 2019 \\ Copyright: Patil et al. This is an open-access article distributed under the terms of the Creative Commons Attribution License 3.0 \\ (CC BY 3.0), which permits unrestricted use, distribution, and reproduction in any medium, provided the original author and source \\ are credited.
}

\section{ABSTRACT}

Background: We planned to compare pemetrexed maintenance with erlotinib maintenance in non squamous non Epidermal Growth Factor Receptor (EGFR) mutated non small cell lung cancer (NSCLC). The null hypothesis for this study was that there would be no difference in quality of life $(\mathrm{QOL})$ between pemetrexed and erlotinib maintenance.

Results: The QL2 scores at 3 months were 63.35 (SD 24.99) in pemetrexed arm and 63.01(SD 23.04) in erlotinib arm (p-0.793). Except in 1 domain, the scores were statistically similar between the 2 arms. In the domain of diarrhea, the score was higher as expected in the erlotinib arm (p-0.048). The median progression free survival was 4.5 months (95\%CI 4.1-4.9 months) in pemetrexed arm versus 4.5 months (95\%CI 3.8-5.2 months) in erlotinib arm (p-0.94). The median overall survival was 16.6 months (15.2-17.9 months) in pemetrexed arm versus 18.3 months (95\% CI 13.75-22.91 months) in erlotinib arm (p-0.49).

Methods: The study was an open label, single centre, parallel, phase 3 randomized study with 1:1 randomization between maintenance pemetrexed arm and erlotinib arm. Adult patients (age > or $=18$ years), with non squamous EGFR mutation, treated with first line palliative therapy, with non progressive disease post 4-6 cycles of pemetrexed-carboplatin were randomized. Primary outcome was change in the score of QOL (Global health status $\{Q L 2\}$ ) at 3 months. We estimated that with 200 patients, the study had $\mathbf{8 0} \%$ power to detect a significant difference between the two groups in the change in the global health status score at 3 months with an alpha error of $5 \%$, with an effect size of 0.3 SD. 


\section{Conclusions: Maintenance pemetrexed post pemetrexed-platinum chemotherapy fails to improve QOL or time to event outcomes over maintenance erlotinib in EGFR mutation negative NSCLC.}

\section{INTRODUCTION}

Treatment of non small cell lung cancer (NSCLC) has evolved over the last one and a half decades. Identification of driver mutations and treatment of these mutated cancers with appropriate tyrosine kinase inhibitors has led to encouraging improvements in outcomes [1-3]. Progress has been made in the management of non driver mutated non squamous NSCLC as well. Pemetrexed-cisplatin regimen is now considered as the favoured regimen for first line treatment in multiple guidelines $[4,5]$. This recommendation is based on a phase 3 study reported by Scagliotti et al where there was an overall survival (OS) advantage over gemcitabine cisplatin for non squamous histologies [6]. In addition, this advantage came with lower frequency of adverse events. There have been advances with regard to maintenance treatment as well. Multiple studies have suggested that maintenance with pemetrexed either as continuation after pemetrexed-platinum therapy or as switch therapy after platinum doublet was feasible and improved survival [7-9]. Maintenance therapy with pemetrexed led to an improvement in median OS by 5.2 months (HR $0.70, p \leq 0.0001$ ) in the study reported by Ciuleanu et al. [10] Such benefits with chemotherapy were unheard of in NSCLC.

Maintenance with pemetrexed, though beneficial, has issues. None of these initial studies have stratified the patients based on their driver mutation status. Further, the intravenous delivery of pemetrexed maintenance meant recurring and continuous hospital visits for the patient. Such frequent visits can be physically and financially distressing and can also lead to non-compliance. Also, there is inconclusive data regarding the cost effectiveness of pemetrexed maintenance [11, 12]. These issues with intravenous maintenance therapy can be overcome by having an oral substitute.

Erlotinib is a reversible tyrosine kinase inhibitor which is approved for treatment of Epidermal Growth Factor Receptor (EGFR) mutation positive NSCLC [13]. However, multiple studies have also shown erlotinib to be active in EGFR activating mutation negative (EGFR neg) patients. In the SATURN study, switch maintenance with erlotinib was associated with a survival benefit, even in EGFR neg patients [14]. With this background, we planned to compare pemetrexed maintenance with erlotinib maintenance in non squamous EGFR neg NSCLC. The null hypothesis for this study was that there would be no difference in quality of life (QOL) between pemetrexed maintenance and erlotinib maintenance.

\section{Highlights}

1) We compared erlotinib and pemetrexed as maintenance therapy; 2) There was no difference in QOL between the 2 arms; 3 ) The PFS and OS were similar between the 2 arms.

\section{RESULTS}

\section{Baseline characteristics}

200 patients were recruited in the above mentioned study period. The consort diagram is shown in Figure 1. The median age of the patient on pemetrexed arm and erlotinib arm were 55 years ( $28-76$ years) \& 56 years $(28-$ 79 years), respectively. All patients had received induction therapy with pemetrexed carboplatin. The stage of these patients at the start of induction pemetrexed -carboplatin was stage IIIB in 11 patients (5.5\%) and stage IV in 189 patients $(94.5 \%)$, respectively. The response rate post induction therapy was $41.8 \%$ and $29.9 \%$, respectively, in pemetrexed arm and erlotinib arm, respectively. Table 1 depicts the baseline characteristics in both arms.

\section{Compliance}

Out of 103 patients randomized on pemetrexed arm, 95 patients $(92.2 \%)$ received at least one cycle of chemotherapy. The median number of cycles of pemetrexed received were 5 (1-33). Pemetrexed was stopped in 77 patients $(74.8 \%)$. The reasons for stopping pemetrexed were progression in 50 patients, patient's choice or intolerable side effects in 24 patients, for logistic reasons in 2 patients and death before progression in 1 patient.

Out of 97 patients randomized on erlotinib arm, 94 patients $(96.9 \%)$ took at least one week of erlotinib. Erlotinib was stopped in 83 patients $(85.5 \%)$. The reason for stopping erlotinib were progression in 65 patients, patient's choice or intolerable side effects in 17 patients and death before progression in 1 patient.

\section{QOL}

One hundred and sixty five patients were eligible for primary endpoint analysis. The baseline QOL scores are shown in Table 2, they were comparable between the 2 arms. The QOL scores in each domain at 3 months are shown in Table 3. The data of QOL scores at 3 months were available for 165 patients. The global health status QOL scores at 3 months were 63.35 (SD 24.99) in pemetrexed arm and 63.01(SD 23.04) in erlotinib arm (p-0.793). Except 
in 1 domain, the scores were statistically similar between the 2 arms. In the domain of diarrhoea, the score was higher in the erlotinib arm (p-0.048). There was no difference in time to deterioration between any QOL domains between the 2 arms.
The data for adverse events was available for 95 patients in the pemetrexed arm and 89 patients in the erlotinib arm. The rate of any grade adverse event between the 2 arms was seen in $87.5 \%(n=84)$ and $97.8 \%$ $(n=87)$ in pemetrexed arm and erlotinib arm, respectively

\section{CONSORT}

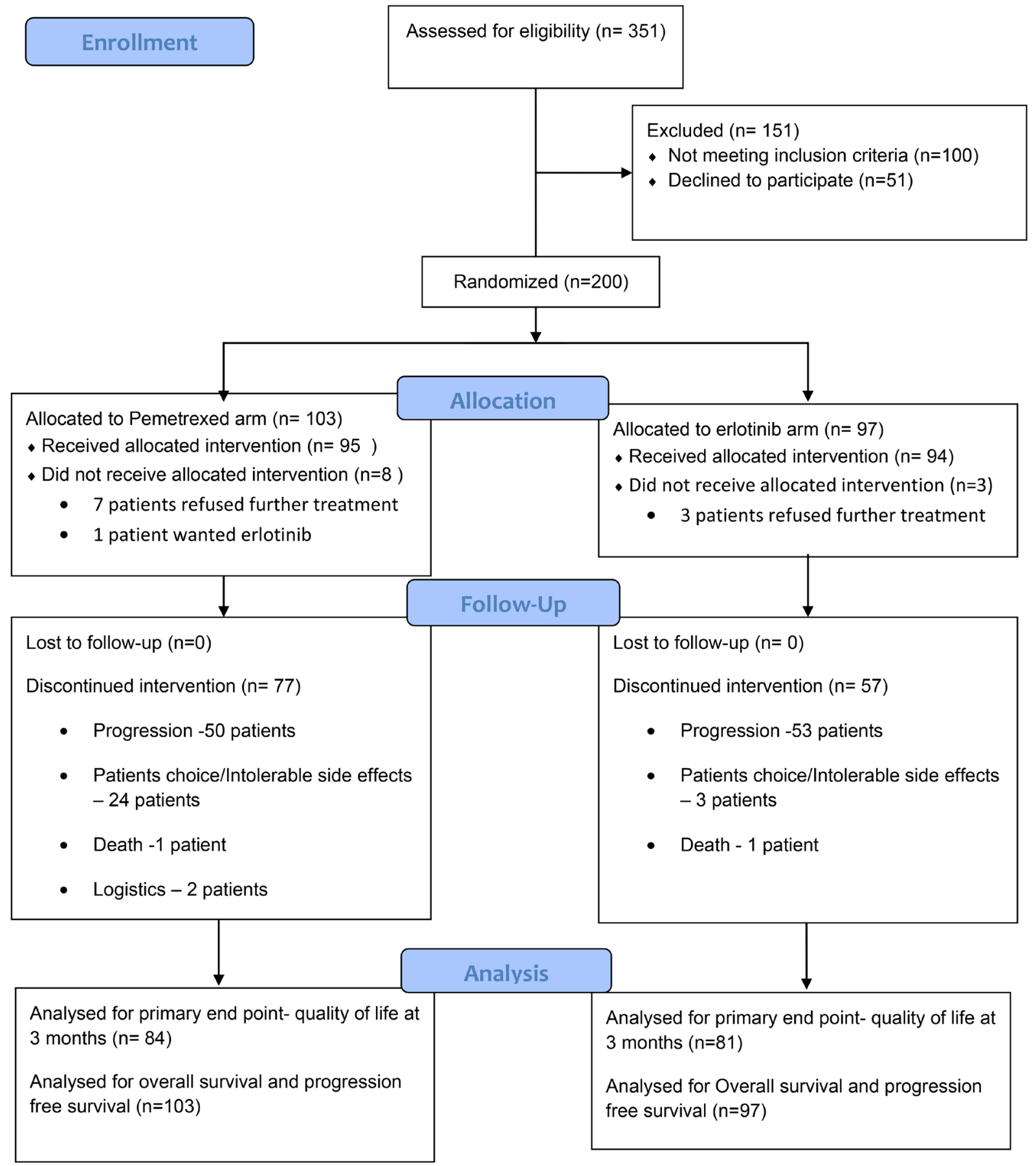

Figure 1: Consort diagram. 
Table 1: Table depicting the baseline characteristics in both arms

\begin{tabular}{|c|c|c|c|}
\hline Arm variables $I$ & Pemetrexed arm $(n=103)$ & Erlotinib arm $(n=97)$ & Overall \\
\hline Median age & 55 years $(28-76)$ & 56 years $(28-79)$ & 55 years $(28-79)$ \\
\hline \multicolumn{4}{|l|}{ Gender } \\
\hline Male & $71(68.9 \%)$ & $61(62.9 \%)$ & $132(66.7 \%)$ \\
\hline Female & $32(31.1 \%)$ & $36(37.1 \%)$ & $68(39.0 \%)$ \\
\hline \multicolumn{4}{|l|}{ ECOG PS } \\
\hline $0-1$ & $98(95.2 \%)$ & $92(94.8 \%)$ & $190(95.0 \%)$ \\
\hline 2 & $01(1.0 \%)$ & - & $1(0.5 \%)$ \\
\hline Missing & $04(3.8 \%)$ & $5(5.2 \%)$ & $9(4.5 \%)$ \\
\hline \multicolumn{4}{|l|}{ Smoking history } \\
\hline Never smoker & $53(51.5 \%)$ & $54(55.7 \%)$ & $107(53.5 \%)$ \\
\hline Previous smoker & $50(48.5 \%)$ & $43(44.3 \%)$ & $93(46.5 \%)$ \\
\hline \multicolumn{4}{|l|}{ Stage } \\
\hline IIIB & $6(5.8 \%)$ & $5(5.2 \%)$ & $11(5.5 \%)$ \\
\hline IV & $97(94.2 \%)$ & $92(94.8 \%)$ & $189(94.5 \%)$ \\
\hline \multicolumn{4}{|l|}{ Sites of metastasis } \\
\hline Brain & $15(14.6 \%)$ & $12(12.4 \%)$ & $27(13.5 \%)$ \\
\hline Bone & $40(38.8 \%)$ & $39(40.2 \%)$ & $79(39.5 \%)$ \\
\hline Liver & $21(20.4 \%)$ & $15(15.5 \%)$ & $36(18.0 \%)$ \\
\hline \multicolumn{4}{|c|}{ Response to induction therapy } \\
\hline Complete response & $1(1 \%)$ & - & $1(0.5 \%)$ \\
\hline Partial response & $42(40.8 \%)$ & $29(29.9 \%)$ & $71(35.5 \%)$ \\
\hline Stable disease & $60(58.3 \%)$ & $68(70.1 \%)$ & $128(64 \%)$ \\
\hline
\end{tabular}

(p-0.011). The rate of grade 3 or above adverse events between the 2 arms were $8.3 \%(n=8)$ and $20.2 \%(n=18)$, respectively. There was a difference in the types of adverse events between the 2 arms. The rate of hematological adverse events was higher in the pemetrexed arm, while that of dermatological adverse events was higher in erlotinib arm. The adverse events between the 2 arms are shown in Table 4.

\section{Time to event outcomes}

The median follow up was 25.36 months. At time of censoring the data, progression was noted in 75 patients in pemetrexed and 70 patients in the erlotinib arm, respectively. The median PFS was 4.5 months $(95 \% \mathrm{CI}$ 4.1-4.9 months) in pemetrexed arm versus 4.5 months (95\%CI 3.8-5.2 months) in the erlotinib arm (p-0.94) (Figure 2). The corresponding hazard ratio was 0.982 (95\%CI 0.709-1.361).

There were 53 deaths in pemetrexed and 48 deaths in erlotinib arm, respectively. The median OS was 16.6 months (15.2-17.9 months) in pemetrexed arm versus 18.3 months (95\% CI 13.75-22.91 months) in erlotinib arm (p-0.49) (Figure 3). The corresponding hazard ratio was 1.222 (95\% CI 0.821-1.818).

\section{DISCUSSION}

The current study upheld the null hypothesis. It clarified that QOL and time to event outcomes (PFS and OS) with continuation of maintenance pemetrexed after pemetrexed carboplatin doublet are similar to those obtained with administration of erlotinib as switch maintenance. These results are a surprise and they challenge the current favored regimen of pemetrexed maintenance after pemetrexed -carboplatin. It renews interest once again in the use of erlotinib in EGFR activating mutation negative NSCLC.

The saga of erlotinib in EGFR activating mutation negative cancer started with the publication of BR.21 results. In this study, patients who had failed one or more 
Table 2: Domain wise QOL score value comparison between Pemetrexed and Erlotinib

\begin{tabular}{|c|c|c|c|}
\hline Domain & Means (SD) in Pemetrexed & Means (SD) in Erlotinib & $P$-value \\
\hline Global health status & $62.90(24.74)$ & $63.65(22.76)$ & 0.692 \\
\hline Physical functioning & $76.57(17.83)$ & $76.714(16.76)$ & 0.919 \\
\hline Role functioning & $84.13(23.07)$ & $87.29(21.02)$ & 0.074 \\
\hline Emotional functioning & $71.11(22.43)$ & $73.64(23.49)$ & 0.167 \\
\hline Cognitive functioning & $83.75(18.35)$ & $84.63(20.52)$ & 0.569 \\
\hline Social functioning & $82.49(24.91)$ & $85.76(23.46)$ & 0.092 \\
\hline Fatigue & $33.58(23.00)$ & $32.70(22.66)$ & 0.629 \\
\hline Nausea and vomiting & $15.50(20.11)$ & $14.13(17.68)$ & 0.368 \\
\hline Pain & $20.37(21.54)$ & $23.40(23.44)$ & 0.089 \\
\hline Dyspnoea & $21.63(25.33)$ & $20.57(23.91)$ & 0.59 \\
\hline Insomnia & $18.45(26.00)$ & $21.04(27.95)$ & 0.22 \\
\hline Appetite loss & $23.22(26.78)$ & $22.58(27.81)$ & 0.767 \\
\hline Constipation & $14.98(25.39)$ & $12.29(22.98)$ & 0.167 \\
\hline Diarrhoea & $8.61(18.57)$ & $12.88(23.26)$ & 0.010 \\
\hline Financial difficulties & $43.26(34.59)$ & $39.83(33.05)$ & 0.206 \\
\hline Dyspnoea & $23.34(18.44)$ & $22.10(19.78)$ & 0.41 \\
\hline Coughing & $35.29(30.42)$ & $35.22(29.16)$ & 0.97 \\
\hline Haemoptysis & $3.27(11.94)$ & $3.07(11.52)$ & 0.82 \\
\hline Sore mouth & $10.48(19.91)$ & $13.59(23.19)$ & 0.06 \\
\hline Dysphagia & $9.17(18.30)$ & $6.97(18.07)$ & 0.13 \\
\hline Peripheral neuropathy & $16.57(23.93)$ & $18.91(25.55)$ & 0.23 \\
\hline Alopecia & $18.91(27.59)$ & $21.04(29.06)$ & 0.34 \\
\hline Pain in chest & $13.57(21.95)$ & $15.48(23.70)$ & 0.29 \\
\hline Pain in arm or shoulder & $12.73(21.52)$ & $14.06(23.76)$ & 0.45 \\
\hline Pain in other parts & $17.04(28.02)$ & $17.61(26.84)$ & 0.79 \\
\hline
\end{tabular}

lines of chemotherapy had received either erlotinib or placebo. Erlotinib, in comparison with placebo, led to an improvement in hazard of progression (hazard ratio, 0.61 , adjusted for stratification categories; $P<0.001$ ) and decreased the hazard of death too (hazard ratio, $0.70 ; P<0.001)$ [15]. Erlotinib was compared against second line chemotherapy agents (standard docetaxel or pemetrexed regimens, at the treating investigators' discretion) in the TITAN study. The median PFS and OS was similar between the 2 arms [17], thus paving way for use of erlotinib in this setting. Both BR.21 and TITAN study were conducted in predominantly EGFR activating mutation negative population. The median PFS in BR.21 and the TITAN study are similar to that seen in our study. In addition, the impact of erlotinib in the maintenance setting against placebo was shown in the SATURN study. Maintenance erlotinib in the SATURN study, irrespective of EGFR activating mutation status led to an improvement in progression free survival [14]. Our study took this a step forward, and demonstrated that even in maintenance setting, erlotinib has activity similar to that of maintenance pemetrexed. Taking all these studies and ours together, it seems that erlotinib has activity in EGFR mutation negative patients and has activity comparable to chemotherapy agents.

The results of our study need to be discussed in consideration with the recent Food and Drug Administration (FDA-United states) decision of removing erlotinib label in EGFR activating mutation negative NSCLC. This decision was based on the recently reported IUNO study. In this study, non EGFR mutated patients post 4 cycles of platinum doublet were randomized to either early erlotinib (maintenance) or placebo. Patients in placebo arm were treated with erlotinib on 
Table 3: Domain wise QOL score value comparison between Pemetrexed and Erlotinib at 3 months

\begin{tabular}{|c|c|c|c|}
\hline Domain & Means (SD) in Pemetrexed & Means (SD) in Erlotinib & $P$-value \\
\hline Global health status & $63.35(24.99)$ & $63.01(23.04)$ & 0.793 \\
\hline Physical functioning & $76.61(16.96)$ & $76.96(16.82)$ & 0.848 \\
\hline Role functioning & $85.28(21.86)$ & $86.06(22.48)$ & 0.746 \\
\hline Emotional functioning & $73.11(24.06)$ & $71.39(22.45)$ & 0.501 \\
\hline Cognitive functioning & $84.66(20.28)$ & $86.45(16.76)$ & 0.379 \\
\hline Social functioning & $83.44(27.31)$ & $85.67(21.94)$ & 0.409 \\
\hline Fatigue & $34.08(24.10)$ & $32.75(22.09)$ & 0.598 \\
\hline Nausea and vomiting & $12.58(17.38)$ & $14.81(17.47)$ & 0.241 \\
\hline Pain & $23.42(25.63)$ & $23.00(22.37)$ & 0.875 \\
\hline Dyspnoea & $24.74(27.86)$ & $19.30(29.93)$ & 0.055 \\
\hline Insomnia & $20.86(26.98)$ & $21.83(31.16)$ & 0.760 \\
\hline Appetite loss & $22.70(27.14)$ & $23.78(29.25)$ & 0.727 \\
\hline Constipation & $16.97(28.53)$ & $12.87(25.88)$ & 0.169 \\
\hline Diarrhoea & $7.15(18.04)$ & $11.31(20.18)$ & 0.048 \\
\hline Financial difficulties & $43.35(33.97)$ & $40.74(35.38)$ & 0.492 \\
\hline Dyspnoea & $23.44(20.62)$ & $22.98(19.30)$ & 0.830 \\
\hline Coughing & $39.46(33.58)$ & $33.71(27.67)$ & 0.085 \\
\hline Haemoptysis & $2.45(9.48)$ & $4.19(14.12)$ & 0.188 \\
\hline Sore mouth & $10.83(20.91)$ & $12.38(22.72)$ & 0.517 \\
\hline Dysphagia & $5.72(15.97)$ & $9.14(20.34)$ & 0.088 \\
\hline Peripheral neuropathy & $14.31(21.90)$ & $16.95(25.73)$ & 0.312 \\
\hline Alopecia & $20.85(28.70)$ & $18.28(26.42)$ & 0.391 \\
\hline Pain in chest & $15.13(26.75)$ & $15.42(21.66)$ & 0.910 \\
\hline Pain in arm or shoulder & $9.20(17.48)$ & $16(25.97)$ & 0.005 \\
\hline Pain in other parts & $15.54(27.03)$ & $15.42(26.44)$ & 0.968 \\
\hline
\end{tabular}

Table 4: Grade 3 or above adverse events between the 2 arms

\begin{tabular}{lcc}
\hline Grade 3-5 adverse events & Pemetrexed arm $(\boldsymbol{n}=\mathbf{9 5})$ & Erlotinib arm $(\boldsymbol{n}=\mathbf{8 9})$ \\
\hline Anemia & $4(4.2 \%)$ & $2(2.3 \%)$ \\
Neutropenia & $3(3.2 \%)$ & - \\
Thrombocytopenia & $1(1.1 \%)$ & $2(2.3 \%)$ \\
SGPT rise & - & $1(1.1 \%)$ \\
Diarrhea & $1(1.1 \%)$ & $4(4.9 \%)$ \\
Skin rash & - & $20(22.5 \%)$ \\
Mucositis & - & $2(2.3 \%)$ \\
Pruritus & & $2(2.3 \%)$ \\
\hline
\end{tabular}


progression, thus effectively making it a comparison of early or maintenance erlotinib versus delayed or second line erlotinib. In this study, there was no impact of early erlotinib on OS, PFS or even disease control rate [18]. Thus the authors concluded that erlotinib should not be used in non EGFR mutated patients. The results of our study and the SATURN study, however, suggest the contrary. The probable reasons for these discrepancies are detailed below. Firstly, the primary endpoint of the IUNO study was OS which is an endpoint influenced by multiple factors, the important one being second line or subsequent therapy. Second line therapy was received by only $50 \%$ of patients from the maintenance erlotinib arm while $78 \%$ received it from the maintenance placebo arm. This was

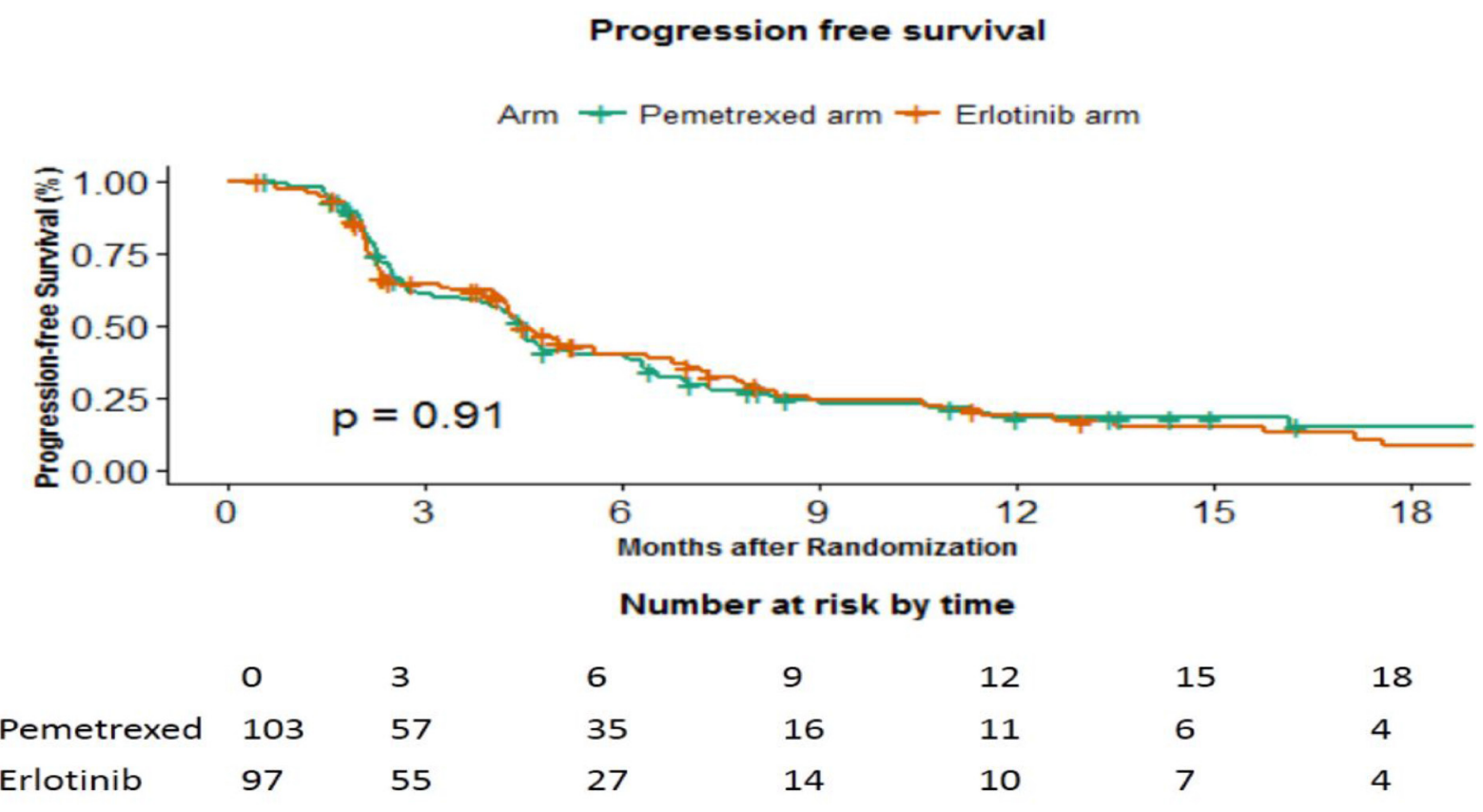

Figure 2: Progression free survival in months between the 2 arms.

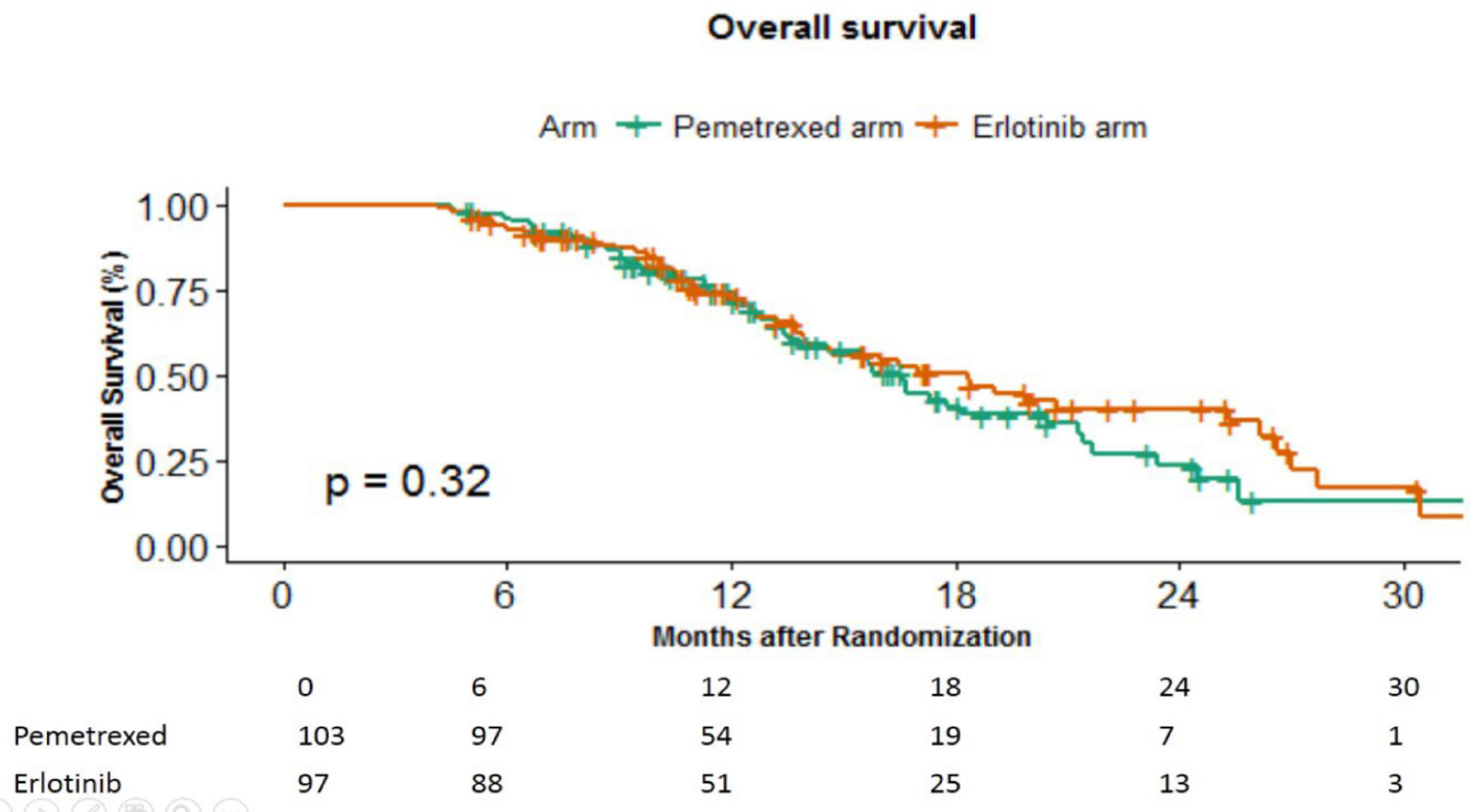

Figure 3: Overall survival in months between the 2 arms. 
in spite of similar rate of progression between both arms. Secondly, the median PFS in the IUNO study was similar in placebo and erlotinib arm. This is an odd finding, considering that 2 previous studies, BR.21 and SATURN, showed an improvement with erlotinib over placebo $[14,15]$. This raises the possibility that such a finding could be a result of either statistical chance or population pharmacogenomics. Whenever trials are performed, the false negative is set at $10-20 \%$. In the IUNO study, it was $20 \%$. Thus there exists a $20 \%$ probability that the results found could be falsely negative. Population pharmacogenomics can further play a role. IUNO was a predominantly east european and east asian study. The pharmacogenomics of these populations are different from Indians and Western population [19]. Pharmacogenetic variation is known in erlotinib and can influence both response and toxicity [20-22].

The current guideline is to consider immunotherapy in first line setting in NSCLC and hence the importance of our results can be questioned. However, PDL1 expression is required for administration of immunotherapy. Pembrolizumab alone can be administered if PDL1 expression is $>50 \%$. For PDL1 expression of $1-49 \%$ a combination of chemotherapy with immunotherapy is required. Hence, chemotherapy without immunotherapy will still be used in patients without driver mutation and PDL1 expression below 1\% [4]. In multiple studies the PDL1 expression $<1 \%$ is seen roughly in $34-47 \%$ of patients [23-25] and hence there will be a substantial proportion of patients who are still candidates for chemotherapy. Accessibility of immunotherapy agents in low and middle income countries is poor [26], and chemotherapy will be the preferred option in these settings.

Adverse event rate seen with maintenance pemetrexed and erlotinib were in accordance with their known side effects. No new safety signals were identified. Pemetrexed was associated with higher rates of myelosuppression, while erlotinib was associated with higher diarrhea rate.

Our study is not without its own limitations. The primary endpoint was quality of life and not PFS or OS. This primary endpoint was selected, as maintenance of QOL in palliative setting was considered as an important aspect of treatment [27]. Improvement in quality of life reflected by symptom control is considered a crucial aspect of maintenance treatment by $90 \%$ of patients [28]. It rarely happens that the results of QOL and time to event outcomes are in different directions. The study randomization was not stratified, hence a higher number of patients in the pemetrexed arm had a response to induction chemotherapy. However despite this imbalance, the pemetrexed arm failed to improve QOL, PFS or OS over the erlotinib arm. There was no placebo arm in the study. At the time of conceptualization of the study, maintenance post 4-6 cycles of pemetrexed-platinum was the standard treatment. Both pemetrexed and erlotinib were approved at that time. Hence the lung medical oncology group felt it was unethical to deny patient of maintenance and use a placebo.

\section{MATERIALS AND METHODS}

\section{Study conduct}

The study was approved by the institutional ethics committee and was conducted in accordance with the ethical norms laid down by declaration of Helsinki, good clinical practice guidelines and local institutional ethics guidelines. The study was registered with CTRI India in August 2014 (CTRI/2014/08/004847). The study was conducted in the department of Medical Oncology at Tata Memorial Hospital, Mumbai, India between 7th November 2014 to 3rd March 2017. All patients recruited in this study provided written informed consent prior to participation in the study. The study was funded by an intramural grant from Tata Memorial centre- Research Administrative Council (TRAC).

\section{Trial design}

The study was an open label, single centre, parallel, phase 3 randomized study with 1:1 randomization between maintenance pemetrexed arm and erlotinib arm. There was no major amendment to the study protocol (Supplementary Appendix 1, see Supplementary Materials) or consent post start of the study.

\section{Participants}

The detailed inclusion and exclusion criteria are provided in the study protocol. In brief, adult patients (age $>$ or $=18$ years) with histologically proven NSCLC (Non squamous), without activating EGFR mutation, with stage IIIB (not suitable for curative intent therapy) or IV, treated with first line palliative therapy, with non progressive disease post 4-6 cycles of pemetrexed-carboplatin, with normal organ functions (absolute neutrophil count $>1500$ / lL, hemoglobin $>8 \mathrm{~g} / \mathrm{dL}$, and platelet count $>100,000 /$ $1 \mathrm{~L}$, serum creatinine $<2 \mathrm{mg} / \mathrm{dL}$, total bilirubin $<1.5$ times the institutional upper limit of normal [ULN], aspartate aminotransferase and alanine aminotransferase levels $<2$ times the institutional ULN), with Eastern Cooperative Oncology Group (ECOG) performance status (PS) of 0-2 and life expectancy of greater than 3 months were included in this study. Patients who had previous exposure to tyrosine kinase inhibitors, who had uncontrolled comorbidities, who had previous treatment for any other cancer or those with uncontrolled infections were excluded.

\section{Randomisation}

Patients post consenting and workup were 1:1 randomized to the 2 intervention arms. The sequence 
generation was done by SK, who served as an independent statistician. The randomization had no stratification factor. The request for randomization was done by the trial coordinator online via email and the randomization was performed and conveyed via email by SK.

\section{Interventions}

The 2 intervention arms in the study were maintenance pemetrexed and erlotinib.

Patients randomized to pemetrexed arm received maintenance intravenous pemetrexed. Pemetrexed was administered intravenously every 3 weekly in a dose of $500 \mathrm{mg} / \mathrm{m} 2$ over $10-15$ minutes. Patients received dexamethasone $8 \mathrm{mg}$ intravenous single dose as antiemetic before pemetrexed. They also received vitamin B12 injection 1000 microgram every 9 weeks and tablet folic acid $5 \mathrm{mg}$ daily while they were on pemetrexed. Patients in the erlotinib arm received tablet erlotinib 150 mg per oral (PO) once daily. Both these interventions were continued till progression of disease or intolerable side effects.

\section{Endpoints}

Primary endpoint of the study was to compare the QOL in both arms at 3 months post randomisation. The secondary endpoints were to compare the progression free survival (PFS), OS and toxicity between the 2 arms. The PFS was defined as time in months from the date of randomization to date of progression or death whichever occurred earlier. The OS was defined as time in months from date of start of pemetrexed-platinum chemotherapy to date of death.

\section{Study methodology}

Patients in both arms, were followed up till death. The dose modifications in both arms were in line with published literature $[6,15]$. Patients in both arms underwent response assessment according to RECIST criteria version 1.1 at 2 monthly intervals. Toxicity was documented in accordance with common terminology criteria for adverse events (CTCAE) version 4.03. European Organisation for Research and Treatment of Cancer (EORTC) QOL scale was used for assessment at baseline and at 3 months using the EORTC-QLQ-C30 and LC13 questionnaire for lung cancer.

\section{Sample size estimation}

Primary outcome was change in the score of QOL (Global health status $\{\mathrm{QL} 2\}$ ) at 3 months. We estimated that with 200 patients, the study had $80 \%$ power to detect a significant difference in the change in the global health status score at 3 months with an alpha error of 5\%, with an effect size of 0.3 standard deviation (SD).

\section{Statistical method}

\section{Quality of life analysis}

The quality of life data was analysed using $R$ software using the "QoLR" package. The missing data was examined using the method suggested by Little et al. [16] It suggested that the data was not missing completely at random. To overcome the chance of bias from the missing data, it was imputed using multivariate imputation by chained equations algorithm using the "mice" package in R. Imputation was not performed for completely missing data for example if QOL was not filled for any reason at 3 months, it was not imputed. The estimation of the scores of EORTC HRQOL questionnaires QLQ-C30 and EORTC QLQ-LC13 questionnaires at baseline and each visit were in accordance with the method defined in the EORTC scoring manual. The mean scores with the standard deviation were calculated. The scores at 3 months were compared using 2 sided student $t$ test for independent samples. Per protocol analysis was performed for the primary endpoint only those patients who had filled the baseline and subsequent 3 month QOL proforma were included.

The QOL data was also collected for visits in addition to the baseline visit and the 3 month visit. The mean scores between all visits between the 2 arms were calculated. A time to deterioration analysis was planned to estimate the time until definitive deterioration. The time until definitive deterioration (TUDD) in QO1 for a specific domain was defined as time interval in months calculated between time to randomization to time to deterioration in that specific QOL domain by 10 or more units or death or progression whichever occurred earlier. The TUDD was compared between the 2 arms for each domain of QOL using log rank test. The A p value of 0.05 was taken as significant and no multiplicity correction was done.

\section{Time to event analysis}

Median follow up was calculated using the reverse Kaplan Meier method. Intention to treat analysis was performed for PFS and OS. The PFS and OS were estimated using the Kaplan Meier method and the 2 arms were compared using the log rank test. The cox regression analysis was used for calculation of the hazard ratio.

\section{CONCLUSIONS}

In conclusion, to our knowledge, the current study is the first study to show that maintenance pemetrexed post pemetrexed-carboplatin chemotherapy fails to improve QOL or time to event outcomes (OS and PFS) over maintenance erlotinib in EGFR mutation negative NSCLC. 


\section{ACKNOWLEDGMENTS}

The study was funded by an intramural grant from Tata Memorial centre- Research Administrative Council (TRAC).

\section{CONFLICTS OF INTEREST}

The authors declare the following financial interests/ personal relationships which may be considered as potential competing interests:

Dr. Noronha reports grants from Dr. Reddy's LaboratoriesĐnc, grants from Amgen, grants from Sanofi Aventis, outside the submitted work.

Dr. Prabhash reports grants from Biocon Ltd, grants from Dr. Reddy's Laboratories Inc, grants from Fresenius Kabi India Pvt Ltd, grants from Alkem Laboratories, grants from Natco Pharma Ltd, grants from BDR Pharmaceutics Intl Pvt Ltd, grants from Roche Holding AG, outside the submitted work.

None of the other authors have anything to declare that maybe considered as potential competing interests.

\section{REFERENCES}

1. Patil VM, Noronha V, Joshi A, Choughule AB, Bhattacharjee A, Kumar R, Goud S, More S, Ramaswamy A, Karpe A, Pande N, Chandrasekharan A, Goel A, et al. Phase III study of gefitinib or pemetrexed with carboplatin in EGFR-mutated advanced lung adenocarcinoma. ESMO Open. 2017; 2:e00168. https://doi.org/10.1136/ esmoopen-2017-000168. [PubMed]

2. Soria JC, Ohe Y, Vansteenkiste J, Reungwetwattana T, Chewaskulyong B, Lee KH, Dechaphunkul A, Imamura F, Nogami N, Kurata T, Okamoto I, Zhou C, Cho BC, et al, and FLAURA Investigators. Osimertinib in Untreated EGFR-Mutated Advanced Non-Small-Cell Lung Cancer. N Engl J Med. 2018; 378:113-25. https://doi.org/10.1056/ NEJMoa1713137. [PubMed]

3. Soria JC, Felip E, Cobo M, Lu S, Syrigos K, Lee KH, Göker E, Georgoulias V, Li W, Isla D, Guclu SZ, Morabito A, Min YJ, et al, and LUX-Lung 8 Investigators. Afatinib versus erlotinib as second-line treatment of patients with advanced squamous cell carcinoma of the lung (LUXLung 8): an open-label randomised controlled phase 3 trial. Lancet Oncol. 2015; 16:897-907. https://doi.org/10.1016/ S1470-2045(15)00006-6. [PubMed]

4. Ettinger DS, Aisner DL, Wood DE, Akerley W, Bauman J, Chang JY, Chirieac LR, D'Amico TA, Dilling TJ, Dobelbower M, Govindan R, Gubens MA, Hennon M, et al. NCCN Guidelines Insights: Non-Small Cell Lung Cancer, Version 5.2018. J Natl Compr Canc Netw. 2018; 16:807-21. https://doi.org/10.6004/jncen.2018.0062. [PubMed]

5. Novello S, Barlesi F, Califano R, Cufer T, Ekman S, Levra MG, Kerr K, Popat S, Reck M, Senan S, Simo GV,
Vansteenkiste J, Peters S; ESMO Guidelines Committee. Metastatic non-small-cell lung cancer: ESMO Clinical Practice Guidelines for diagnosis, treatment and follow-up. Ann Oncol. 2016; 27:v1-v27. https://doi.org/10.1093/ annonc/mdw326. [PubMed]

6. Scagliotti GV, Parikh P, von Pawel J, Biesma B, Vansteenkiste J, Manegold C, Serwatowski P, Gatzemeier U, Digumarti R, Zukin M, Lee JS, Mellemgaard A, Park K, et al. Phase III study comparing cisplatin plus gemcitabine with cisplatin plus pemetrexed in chemotherapy-naive patients with advanced-stage non-small-cell lung cancer. J Clin Oncol. 2008; 26:3543-51. https://doi.org/10.1200/ JCO.2007.15.0375. [PubMed]

7. Tomasini P, Barlesi F, Mascaux C, Greillier L. Pemetrexed for advanced stage nonsquamous non-small cell lung cancer: latest evidence about its extended use and outcomes. Ther Adv Med Oncol. 2016; 8:198-208. https://doi. org/10.1177/1758834016644155. [PubMed]

8. Paz-Ares LG, de Marinis F, Dediu M, Thomas M, Pujol JL, Bidoli P, Molinier O, Sahoo TP, Laack E, Reck M, Corral J, Melemed S, John W, et al. PARAMOUNT: final overall survival results of the phase III study of maintenance pemetrexed versus placebo immediately after induction treatment with pemetrexed plus cisplatin for advanced nonsquamous non-small-cell lung cancer. J Clin Oncol. 2013; 31:2895-902. https://doi.org/10.1200/ JCO.2012.47.1102. [PubMed]

9. Gentzler RD, Patel JD. Maintenance treatment after induction therapy in non-small cell lung cancer: latest evidence and clinical implications. Ther Adv Med Oncol. 2014; 6:4-15. https://doi.org/10.1177/1758834013510589. [PubMed]

10. Ciuleanu T, Brodowicz T, Zielinski C, Kim JH, Krzakowski M, Laack E, Wu YL, Bover I, Begbie S, Tzekova V, Cucevic B, Pereira JR, Yang SH, et al. Maintenance pemetrexed plus best supportive care versus placebo plus best supportive care for non-small-cell lung cancer: a randomised, double-blind, phase 3 study. Lancet. 2009; 374:1432-40. https://doi.org/10.1016/S0140-6736(09)61497-5. [PubMed]

11. Zeng X, Peng L, Li J, Chen G, Tan C, Wang S, Wan X, Ouyang L, Zhao Z. Cost-effectiveness of continuation maintenance pemetrexed after cisplatin and pemetrexed chemotherapy for advanced nonsquamous non-small-cell lung cancer: estimates from the perspective of the Chinese health care system. Clin Ther. 2013; 35:54-65. https://doi. org/10.1016/j.clinthera.2012.12.013. [PubMed]

12. Matter-Walstra K, Joerger M, Kühnel U, Szucs T, Pestalozzi B, Schwenkglenks M. Cost-effectiveness of maintenance pemetrexed in patients with advanced nonsquamous-cell lung cancer from the perspective of the Swiss health care system. Value Health. 2012; 15:65-71. https://doi.org/10.1016/j.jval.2011.08.1737. [PubMed]

13. Cohen MH, Johnson JR, Chattopadhyay S, Tang S, Justice R, Sridhara R, Pazdur R. Approval summary: erlotinib maintenance therapy of advanced/ 
metastatic non-small cell lung cancer (NSCLC). Oncologist. 2010; 15:1344-51. https://doi.org/10.1634/ theoncologist.2010-0257. [PubMed]

14. Cappuzzo F, Ciuleanu T, Stelmakh L, Cicenas S, Szczésna A, Juhász E, Esteban E, Molinier O, Brugger W, Melezínek I, Klingelschmitt G, Klughammer B, Giaccone $G$, and SATURN investigators. Erlotinib as maintenance treatment in advanced non-small-cell lung cancer: a multicentre, randomised, placebo-controlled phase 3 study. Lancet Oncol. 2010; 11:521-29. https://doi. org/10.1016/S1470-2045(10)70112-1. [PubMed]

15. Shepherd FA, Rodrigues Pereira J, Ciuleanu T, Tan EH, Hirsh V, Thongprasert S, Campos D, Maoleekoonpiroj S, Smylie M, Martins R, van Kooten M, Dediu M, Findlay B, et al, and National Cancer Institute of Canada Clinical Trials Group. Erlotinib in previously treated non-small-cell lung cancer. N Engl J Med. 2005; 353:123-32. https://doi. org/10.1056/NEJMoa050753. [PubMed]

16. Little RJ, Rubin DB. Statistical Analysis with Missing Data. 2nd Edition, John Wiley \& Sons, Hoboken. 2014. https:// doi.org/10.1002/9781119013563.

17. Ciuleanu T, Stelmakh L, Cicenas S, Miliauskas S, Grigorescu AC, Hillenbach C, Johannsdottir HK, Klughammer B, Gonzalez EE. Efficacy and safety of erlotinib versus chemotherapy in second-line treatment of patients with advanced, non-small-cell lung cancer with poor prognosis (TITAN): a randomised multicentre, open-label, phase 3 study. Lancet Oncol. 2012; 13:300-08. https://doi.org/10.1016/S1470-2045(11)70385-0. [PubMed]

18. Cicènas S, Geater SL, Petrov P, Hotko Y, Hooper G, Xia F, Mudie N, Wu YL. Maintenance erlotinib versus erlotinib at disease progression in patients with advanced non-small-cell lung cancer who have not progressed following platinum-based chemotherapy (IUNO study). Lung Cancer. 2016; 102:30-37. https://doi.org/10.1016/j. lungcan.2016.10.007. [PubMed]

19. Liu W, Innocenti F, Chen P, Das S, Cook EH Jr, Ratain MJ. Interethnic difference in the allelic distribution of human epidermal growth factor receptor intron 1 polymorphism. Clin Cancer Res. 2003; 9:1009-12. [PubMed]

20. Phelps MA, Stinchcombe TE, Blachly JS, Zhao W, Schaaf LJ, Starrett SL, Wei L, Poi M, Wang D, Papp A, Aimiuwu J, Gao Y, Li J, et al. Erlotinib in African Americans with advanced non-small cell lung cancer: a prospective randomized study with genetic and pharmacokinetic analyses. Clin Pharmacol Ther. 2014; 96:182-91. https://doi.org/10.1038/clpt.2014.93. [PubMed]
21. Fukudo M, Ikemi Y, Togashi Y, Masago K, Kim YH, Mio T, Terada T, Teramukai S, Mishima M, Inui K, Katsura T. Population pharmacokinetics/pharmacodynamics of erlotinib and pharmacogenomic analysis of plasma and cerebrospinal fluid drug concentrations in Japanese patients with non-small cell lung cancer. Clin Pharmacokinet. 2013; 52:593-609. https://doi.org/10.1007/s40262-013-0058-5. [PubMed]

22. Rudin CM, Liu W, Desai A, Karrison T, Jiang X, Janisch L, Das S, Ramirez J, Poonkuzhali B, Schuetz E, Fackenthal DL, Chen P, Armstrong DK, et al. Pharmacogenomic and pharmacokinetic determinants of erlotinib toxicity. J Clin Oncol. 2008; 26:1119-27. https:// doi.org/10.1200/JCO.2007.13.1128. [PubMed]

23. Brahmer J, Reckamp KL, Baas P, Crinò L, Eberhardt WE, Poddubskaya E, Antonia S, Pluzanski A, Vokes EE, Holgado E, Waterhouse D, Ready N, Gainor J, et al. Nivolumab versus Docetaxel in Advanced Squamous-Cell Non-SmallCell Lung Cancer. N Engl J Med. 2015; 373:123-35. https:// doi.org/10.1056/NEJMoa1504627. [PubMed]

24. Borghaei H, Paz-Ares L, Horn L, Spigel DR, Steins M, Ready NE, Chow LQ, Vokes EE, Felip E, Holgado E, Barlesi F, Kohlhäufl M, Arrieta O, et al. Nivolumab versus Docetaxel in Advanced Nonsquamous Non-Small-Cell Lung Cancer. N Engl J Med. 2015; 373:1627-39. https:// doi.org/10.1056/NEJMoa1507643. [PubMed]

25. Herbst RS, Baas P, Kim DW, Felip E, Pérez-Gracia JL, Han JY, Molina J, Kim JH, Arvis CD, Ahn MJ, Majem M, Fidler MJ, de Castro G Jr, et al. Pembrolizumab versus docetaxel for previously treated, PD-L1-positive, advanced non-small-cell lung cancer (KEYNOTE-010): a randomised controlled trial. Lancet. 2016; 387:1540-50. https://doi. org/10.1016/S0140-6736(15)01281-7. [PubMed]

26. Ruff P, Al-Sukhun S, Blanchard C, Shulman LN. Access to Cancer Therapeutics in Low- and Middle-Income Countries. Am Soc Clin Oncol Educ Book. 2016; 35:58-65. https://doi.org/10.1200/EDBK_155975. [PubMed]

27. Cherny NI, Dafni U, Bogaerts J, Latino NJ, Pentheroudakis G, Douillard JY, Tabernero J, Zielinski C, Piccart MJ, de Vries EG. ESMO-Magnitude of Clinical Benefit Scale version 1.1. Ann Oncol. 2017; 28:2340-66. https://doi.org/10.1093/annonc/mdx310. [PubMed]

28. Peeters L, Sibille A, Anrys B, Oyen C, Dooms C, Nackaerts K, Wauters I, Vansteenkiste J. Maintenance therapy for advanced non-small-cell lung cancer: a pilot study on patients' perceptions. J Thorac Oncol. 2012; 7:1291-95. https://doi.org/10.1097/JTO.0b013e31825879ea. [PubMed] 